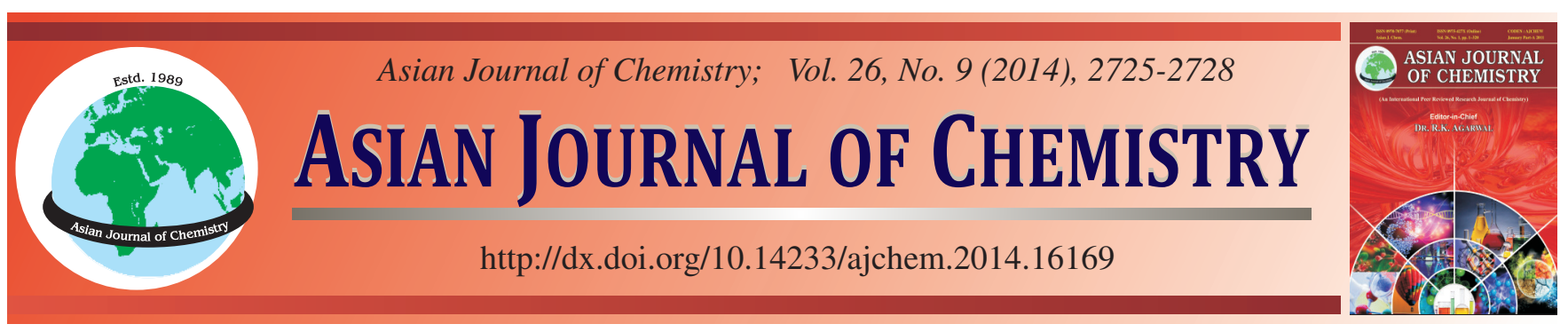

\title{
Speciation of Iodine in Environmental Water System
}

WeINA ZHANG ${ }^{1,2, *}$

${ }^{1}$ Key Laboratory of Preparation and Applications of Environmental Friendly Materials, Ministry of Education, Jilin Normal University, Siping 136000, P.R. China

${ }^{2}$ College of Chemistry, Jilin Normal University, Siping 136000, Jilin Province, P.R. China

*Corresponding author: E-mail: nana820616@aliyun.com

Received: 8 August 2013;

Accepted: 11 December 2013;

Published online: 28 April 2014;

AJC-15107

The speciation in environmental water system was selected as target in this paper. The contents of total iodine and its speciation in environmental water system including groundwater, tap water, pure water, lake water, rain water, snow water and sea water which used as comparison with surface water had been discussed. As the results revealed, the contents and speciation of iodine in different environmental water system were different from each other. The region of Changchun of China was a section of moderate iodine which judged by tap water, ground water and lake water. However and the existent speciation of iodine in these three waters were $\mathrm{IO}_{3}{ }^{-}$for tap water, $\mathrm{I}^{-}$for ground water with nearly both were $100 \%$ and $\mathrm{IO}_{3}^{-}, \mathrm{I}^{-}$and other perhaps organics species for lake water, rain water, snow water and sea water.

Keywords: Environmental water, Iodate, Iodide, Iodine, Speciation.

\section{INTRODUCTION}

Iodine is one of the essential trace elements for composing thyroid hormones in human body and some other biological species. Iodine deficiency leads to hypothyroidism and various disorders associated with growth and development, like dwarfism, mental retardation and neuromuscular defects ${ }^{1,2}$. On the contrary, excessive intake of iodine also causes high-iodine goiter and nervous disease. So it is very important to control the daily intake of iodine by healthy population ${ }^{3-6}$. Nowadays, it is found that elemental bioactivity and bioavailability for creatures is more related with its species than its total content, so more and more interest is focused on the study of the status of the objective element present in food, environmental and biological substances, which is so-called elemental specia$\operatorname{tion}^{7-10}$. Thus, the total analysis and characterization of iodine species in samples is an important pursuit. The daily intake of iodine for people is mainly from food and drinking water, it was reported that the lowest and highest bioavailability of iodine in different foods was $2 \%$ and $99 \%$, respectively ${ }^{11}$ and the food have various and ambulatory characteristic, which will be different from different people, so, the water iodine has been regarded as an important index for evaluation whether one area is iodine deficiency or excess.

Iodine is an electronegative element with oxidation states of $-1,0,+1,+3,+5$ and +7 and exists in multiform in aqueous solution. Iodine is a redox sensitive element forming a wide variety of organic and inorganic compounds and the most common inorganic forms of iodine are I-(iodide), HOI (hypoiodous acid), $\mathrm{I}_{2}$ (elemental iodine) and $\mathrm{IO}_{3}^{-}$(iodate) in natural environmental Eh-pH conditions ${ }^{12,13}$. Speciation of iodine in natural water depends on several parameters including water chemistry, $\mathrm{pH}$, Eh, temperature and organic productivity. For example, in seawater, iodine mainly exists as iodate, iodide and minor organic iodine ${ }^{14}$. In fresh water, such as rivers, lakes and rain, iodine exists also as iodide, iodate and organic iodine, but the relative concentration of organic iodine is different from that of seawater ${ }^{15,16}$.

It is well known that water system is an important part of environmental system. It is an important place for the survival and development of human society, is the medium of conversion and migration of elements in environmental circulation, is an important source of human intake of iodine. So, the study on speciation of iodine in environmental water system in this paper has important theoretical value and practical significance.

The natural water in one important city in Northeast area of China were selected as studied target and analysis of environmental geochemical behavior of iodine in this area would be studied through the speciation of iodine, which not only provides theoretical basis of conversion conditions and migration rules for further study of iodine in natural environment, but also provides important practical significance for prevention, control of local disease and further expansion of local disease general investigation. 


\section{EXPERIMENTAL}

The instruments, reagents used in this study and the optimal instrumental operating parameters were all same as that of our previous work ${ }^{17,18}$ and the contents of total iodine and speciation of iodine were determined according to the references ${ }^{17,18}$ via inductively plasma mass spectrometry (ICP-MS) and short column ion chromatography coupled with inductively plasma mass spectrometry (IC-ICP-MS) which proposed by ourselves, respectively.

Sample collection: $100 \mathrm{~mL}$ water was collected for all environmental water samples and the polyethylene bottles, polyethylene centrifugal tubes used for sample collection and experiments were washed using $30 \%(\mathrm{v} / \mathrm{v}) \mathrm{HNO}_{3}$ and collected water samples. Ground water, tap water samples were collected according to the Chinese national standard and seven district of Chaoyang District in Changchun City were selected for collection of tap water and ten samples were collected in every district and the numbers of mean value in every district were TW1, TW2, TW3, TW4, TW5, TW6 and TW7, respectively. One district was selected in Changchun City for collection of ground water and ten samples with the number GW of mean value. Three pure water samples were purchased in local market with the number of PW1, PW2 and PW3.

Rain water, snow water, sea water and lake water of Changchun samples were collected according to the Chinese national standard. 40 rain water and 40 snow water samples were collected at 4 different months and 10 samples were collected at every time and different location, then mean value of the determination results of these 10 samples were numbered with RW1, RW2, RW3, RW4 and SW1, SW2, SW3, SW4, respectively. 4 sea water samples collected from Qingdao (China) and Dalian (China) were numbered with SeaW1, SeaW2 and SeaW3, SeaW4.

South lake of Changchun (China) was selected as source of lake water samples. A total of 6 locations were settled according to the different function of water in different area coverage and different characteristics of water which are affected by recharged flow direction, pollution sources, emerging plants, eyot and action of human being, 30 samples were collected throughout the South Lake, that is to say, 5 samples were collected in every location. Station 1 is near the northwest lake shore with a large of hydrophytes including water lily and hyacinth; Station 2 is near the eyot in the middle of lake, where is the recreation ground of walking and other actions; Station 3 is near the west lake shore, which is near the birch wood. Station 4 is near the bathing beach swimming area and the region is disturbed more seriously by human. Station 5 is near the South Lake Bridge, which is mainly effected seriously by passing vehicles on Bridge. Station 6 is near the yacht berth, which is also disturbed more seriously by human and shipping. Then, mean value of the determination results of these 30 samples in 6 locations were numbered with SLW1, SLW2, SLW3, SLW4, SLW5 and SLW6.

General procedure of sample treatment: All collected water samples were covered and took back laboratory as soon as possible and filtered through a Millipore $0.22 \mu \mathrm{m}$ membrane filter. And all filtered water samples were stored at $4{ }^{\circ} \mathrm{C}$ until analysis with not dilution before determination. The blank solution was detected at the same time.

\section{RESULTS AND DISCUSSION}

Speciation of environmental water system: The contents of total iodine and speciation in all collected environmental water samples were detected and the results were showed in Table-1. Table- 1 showed that the speciation of iodine in sea water and lake water are both mainly $\mathrm{IO}_{3}{ }^{-}$and $\mathrm{I}^{-}$and the contents of $\mathrm{IO}_{3}{ }^{-}$are more than that of $\mathrm{I}^{-}$. However, the additional results of the two ions are lower than total iodine contents of the same sample which directly determined by ICP-MS, the difference may be organic iodine or elemental iodine. The reasons may attribute to the environment of these two water systems, in which many phytoplanktons and aquatic animal are living and can cause various organic matters, so, organic iodine like methyl iodide will be caused in this environment of organic matters.

The speciation of iodine in tap water are all $\mathrm{IO}_{3}{ }^{-}$and the values are nearly same as the total iodine contents of the same sample which directly determined by ICP-MS. Because tap water will pass a series of processes such as filtration, subsidence, ion exchange, disinfection and so on before sent to the user, in which the used strong oxidant and the oxygen in air are easy to oxidize $\mathrm{I}^{-}$into $\mathrm{IO}_{3}^{-}$.

The speciation of iodine in rain water and snow water are both $\mathrm{IO}_{3}^{-}$and $\mathrm{I}^{-}$and the contents of $\mathrm{I}^{-}$are more than that of $\mathrm{IO}_{3}^{-}$. However, the contents of these two ions are both much lower than total iodine contents of the same sample which directly determined by ICP-MS. According to the references $^{19,20}$, the difference may be organic iodine, which is mainly determined by the circle of iodine in the environmental system.

Iodine in three pure water samples are non-existent, which shows that iodine has been removed through a group of processing operations including ion exchange, reverse osmosis and ultrafiltration.

$\mathrm{I}^{-}$is the existent speciation of iodine in ground water, mainly because of the groundwater environment which belongs to anaerobic conditions and is unfavorable to the formation of oxidation state $\mathrm{IO}_{3}^{-}$. Therefore, iodide is stable iodine speciation in ground water

Analysis of environmental geochemistry of iodine in water system: In this paper, the determination of iodine in different environmental water systems has revealed the contents of iodine in sea water are higher than that of in continental water, so, the residents around coastal areas can absorb sufficient iodine through volatile of iodine and circle of iodine in the water-air-rock-soil-plant system, which are the reasons of that the residents in these areas are not prone to iodine deficiency disease. On contrary, the iodine taken into the body of residents away from coastal areas through various iodine circles are less than before mentioned people, which proves the theories of scholars ${ }^{21}$, the distribution of Iodine deficiency disorders diseases is lowest around coastal areas and highest around mountain areas.

The non-existence of iodine in pure water reminds people should not try to take into pure water instead of tap water and groundwater as drinking water daily in order to avoid iodine deficiency disorders diseases, especially in the mainland or in the mountain areas. 


\begin{tabular}{|c|c|c|c|c|}
\hline \multirow{3}{*}{ Sample } & \multicolumn{4}{|c|}{$\begin{array}{c}\text { TABLE-1 } \\
\text { CONTENTS OF TOTAL IODINE AND SPECIATION IN ENVIRONMENTAL WATER SYSTEM }\end{array}$} \\
\hline & \multirow{2}{*}{ Sample category } & \multirow{2}{*}{ Total iodine $^{\mathrm{a}}\left(\text { mean } \pm \mathrm{SD}^{\mathrm{b}}\right)^{\mathrm{d}}$} & \multicolumn{2}{|c|}{ Determined by IC-ICP-MS } \\
\hline & & & $\mathrm{IO}_{3}^{-\mathrm{c}}\left(\text { mean } \pm \mathrm{SD}^{\mathrm{b}}\right)^{\mathrm{d}}$ & $\mathrm{I}^{-}\left(\text {mean } \pm \mathrm{SD}^{\mathrm{b}}\right)^{\mathrm{d}}$ \\
\hline GW & Ground water & $33.44 \pm 0.55$ & - & $33.96 \pm 1.16$ \\
\hline TW1 & \multirow{7}{*}{ Tap water } & $35.43 \pm 0.64$ & $35.12 \pm 1.24$ & - \\
\hline TW2 & & $36.21 \pm 0.71$ & $35.97 \pm 1.26$ & - \\
\hline TW3 & & $34.92 \pm 0.59$ & $34.25 \pm 1.12$ & - \\
\hline TW4 & & $33.65 \pm 0.60$ & $33.19 \pm 1.06$ & - \\
\hline TW5 & & $35.92 \pm 0.61$ & $36.04 \pm 1.38$ & - \\
\hline TW6 & & $34.86 \pm 0.56$ & $34.36 \pm 1.25$ & - \\
\hline TW7 & & $33.91 \pm 0.43$ & $34.08 \pm 1.19$ & - \\
\hline PW1 & \multirow{3}{*}{ Pure water } & - & - & - \\
\hline PW2 & & - & - & - \\
\hline PW3 & & - & - & - \\
\hline RW1 & \multirow{4}{*}{ Rain water } & $3.560 \pm 0.04$ & $0.598 \pm 0.07$ & $0.968 \pm 0.15$ \\
\hline RW2 & & $4.014 \pm 0.06$ & $0.702 \pm 0.09$ & $1.051 \pm 0.18$ \\
\hline RW3 & & $4.635 \pm 0.04$ & $0.788 \pm 0.08$ & $1.205 \pm 0.12$ \\
\hline RW4 & & $3.246 \pm 0.03$ & $0.539 \pm 0.06$ & $0.873 \pm 0.09$ \\
\hline SW1 & \multirow{4}{*}{ Snow water } & $4.125 \pm 0.04$ & $0.681 \pm 0.08$ & $1.150 \pm 0.19$ \\
\hline SW2 & & $3.064 \pm 0.02$ & $0.545 \pm 0.06$ & $0.843 \pm 0.10$ \\
\hline SW3 & & $1.268 \pm 0.01$ & $0.218 \pm 0.03$ & $0.338 \pm 0.03$ \\
\hline SW4 & & $0.624 \pm 0.006$ & $0.118 \pm 0.02$ & $0.172 \pm 0.02$ \\
\hline SLW1 & \multirow{6}{*}{ Lake water } & $21.13 \pm 0.46$ & $15.52 \pm 0.72$ & $2.18 \pm 0.21$ \\
\hline SLW2 & & $18.29 \pm 0.42$ & $15.02 \pm 0.68$ & $2.36 \pm 0.18$ \\
\hline SLW3 & & $20.05 \pm 0.47$ & $15.93 \pm 0.80$ & $1.20 \pm 0.14$ \\
\hline SLW4 & & $17.24 \pm 0.38$ & $14.85 \pm 0.62$ & $2.03 \pm 0.17$ \\
\hline SLW5 & & $16.04 \pm 0.31$ & $13.47 \pm 0.58$ & $2.24 \pm 0.19$ \\
\hline SLW6 & & $16.43 \pm 0.35$ & $13.39 \pm 0.56$ & $2.18 \pm 0.18$ \\
\hline SeaW1 & \multirow{4}{*}{ Sea water } & $35.80 \pm 0.69$ & $23.81 \pm 0.92$ & $8.06 \pm 0.48$ \\
\hline SeaW2 & & $36.02 \pm 0.71$ & $24.25 \pm 0.98$ & $8.23 \pm 0.45$ \\
\hline SeaW3 & & $40.33 \pm 0.79$ & $28.72 \pm 1.03$ & $9.06 \pm 0.53$ \\
\hline SeaW4 & & $40.66 \pm 0.81$ & $29.04 \pm 1.12$ & $8.35 \pm 0.50$ \\
\hline
\end{tabular}

Changchun was section of iodine deficiency (the section is one of iodine deficiency when the value of water iodine $<10 \mu \mathrm{g} / \mathrm{L}{ }^{22}$ ) which judged by atmospheric precipitation (rain water and snow water), and the contents of iodine in rain water and snow water are negligible, so, it is very difficult to play the effect of iodine supplementation by atmospheric dry and wet deposition of Changchun City. However, the content of iodine in South lake of Changchun is moderate (The section is one of moderate iodine when the value of water iodine is between $10-125 \mu \mathrm{g} / \mathrm{L}^{22}$ ) and South Lake is the main place of leisure and entertainment for residents of Changchun City and it is the main source of environmental greening water and road spraying water. Thus, the content of iodine in air of Changchun City could be increase through environmental green and spraying road using South Lake water, which will add iodine content in atmospheric precipitation, so that the absorbance of iodine from air will increase for residents.

However, the main sources of iodine for residents of Changchun are drinking water and iodized salt, according to reference ${ }^{17}$, the edible salt in Changchun city are all iodized salt and the contents of iodine in which are moderate. And Changchun was section of moderate iodine which judged by the contents of iodine in ground water and tap water, which will indicate that the residents in this area are not prone to iodine deficiency disorders diseases. Coupled with the popularity of national iodized salt, there is no danger of iodine deficiency for residents of Changchun City, although this city is away from sea, which is the reason of why the contents of urine iodine in this area are higher in reference ${ }^{17}$.

\section{Conclusion}

The contents, speciation, reasons of speciation and their behaviors in environmental geochemistry of iodine in different environmental water system had been studied in this work. The results revealed that the contents and speciation of iodine in different environmental water system were different from each other. In a word, the content of iodine in seawater was higher than that in land water. The iodine was existed as $\mathrm{IO}_{3}{ }^{-}$ and $\mathrm{I}^{-}$in seawater and Changchun South lake water and the contents were moderate. Changchun was section of iodine deficiency which judged by atmospheric precipitation, the total content of $\mathrm{IO}_{3}^{-}$and $\mathrm{I}^{-}$was fewer than half of total iodine. Changchun was section of moderate iodine which judged by tap water and groundwater, however, the existent speciation of iodine in these two waters were $\mathrm{IO}_{3}{ }^{-}$for tap water and $\mathrm{I}^{-}$for groundwater, respectively, nearly both were $100 \%$. And there was not iodine with any species in pure water, so, it is suggested that people should not drink pure water in long-term to avoid iodine deficiency disease.

In a word, the study of speciation for iodine in this paper not only provides important theoretical value for environmental geochemistry, by monitoring the iodine speciation in local environment also has a certain practical value on human health. 


\section{ACKNOWLEDGEMENTS}

This work was financially supported by Startup Project of Doctor scientific research of Jilin Normal University (2012001).

\section{REFERENCES}

1. F. Delange, H. Burgi, Z.P. Chen and J.T. Dunn, Thyroid, 12, 915 (2002).

2. WHO, UNICEF, ICCIDD Assessment of iodine deficiency disorders and monitoring their elimination: a guide for programme managers, World Health Organization, Geneva (2001).

3. M. Dermelj, Z. Slejkovec, A.R. Byrne, P. Stegnar, V. Stibilj and M. Rossbach, Fresenius J. Anal. Chem., 338, 559 (1990).

4. R.R. Rao and A. Chatt, Anal. Chem., 63, 1298 (1991).

5. T. Shinonaga, M.H. Gerzabek, F. Strebl and Y. Muramatsu, Sci. Total Environ., 267, 33 (2001).

6. P.R. Bhagat, R. Acharya, A.G.C. Nair, A.K. Pandey, N.S. Rajurkar and A.V.R. Reddy, Food Chem., 115, 706 (2009).

7. P. Xu, J.M. Sun and H.W. Sun, Chin. Spectrosc. Spect. Anal., 23, 1203 (2003)

8. I. Lamy, S. Bourgeois and A. Bermond, J. Environ. Qual., 22, 731 (1993).

9. G.E. Batley, S.C. Apte and J.L. Stauber, Aust. J. Chem., 57, 903 (2004).

10. Y.H. Zhao, R.Q. Huang, K.Y. Li, B.K. Xiao and J.Y. Yang, Med. Instrum., 3, 1 (2009).

11. K.A. Schwehr and P.H. Santschi, Anal. Chim. Acta, 482, 59 (2003).
12. Y. Liu and H.R. Gunten, Migration Chemistry and Behaviour of Iodine Relevent to Geological Disposal of Radioactive Wastes, A Literature Review with a Compilation of Sorption Data, PSI-16, Paul Scherrer Institute, Switzerland (1988).

13. R. Michel, K. Klipsch, Th. Ernst, M. Gorny, D. Jakob, J. Vahlbruch, H.-A. Synal and C. Schnabel, Ableitung von radioökologischen Parametern aus dem langfristigen Eintrag von Iod-129 (in German) Abschlussbericht zum Forschungsvorhaben StSch 4285, August 2004, in: Schriftenreihe Reaktorsicherheit und Strahlenschutz, BMU-2004650, ISSN 1612-6386, http://www.bmu.de/strahlenschutz/doc6872.php und www.zsr.unihannover.de.

14. G.T.F. Wong, Rev. Aquat. Sci., 45, 45 (1991).

15. P. Vaattovaara, P.E. Huttunen, Y.J. Yoon, J. Joutsensaari, K.E.J. Lehtinen, C.D. O'Dowd and A. Laaksonen, Atmos. Chem. Phys., 6, 4601 (2006).

16. C. Reifenhäuser and K.G. Heumann, Fresenius J. Anal. Chem., 336, 559 (1990)

17. W.N. Zhang, H.T. Chen, X.J. Xie and J.L. Lu, J. Jilin Normal Univ. (Nat. Sci. Ed.), 31, 6(2010).

18. W.N. Zhang, X.Q. Liu, X.Y. Jia, Y. Han, X.L. Liu, X.J. Xie, J.L. Lu, T.C. Duan and H.T. Chen, Chromatographia, 72, 1009 (2010).

19. B.S. Gilfedder, M. Petri and H. Biester, J. Geophys. Res., 112, D07301 (2007).

20. B.S. Gilfedder, M. Petri and H. Biester, Atmos. Chem. Phys., 7, 2661 (2007).

21. D.Z. Dan and P. Li, J. Mineral Petrol, 14, 69 (1994).

22. Z.P. Chen, D.R. Liu and Y.K. Yang, Chin. J. Endemiology, 17, 385 (1998). 